ing videos used in the course come from the Wiimali website, a dynamic virtual community, which was created to help students understand threshold concepts such as social justice, patient safety and person-centred care. A mental health consumer is introduced to demonstrate mind-body-spirit connection (Levett-Jones et al., 2015) but none of the videos selected for the course focuses on recovery because when they were created it was with a general teaching purpose in mind. One assignment in the course assesses students' understanding of recovery-oriented mental health nursing as one component of the marking criteria; however students often fail to understand what recovery in contemporary mental health nursing practice means and so cannot demonstrate their understanding in their assignment. This paper discusses some possible reasons for this.

\section{DEFINING RECOVERY}

McKenna et al. (2016) differentiate clinical recovery, with its emphasis on symptom reduction and improved social function overseen by mental health professionals, from the contemporary understanding of recovery where personal recovery is "the unique journey of the individual toward a life worth living” (p. 168). This journey involves a continuous journey, hope, autonomy, collaborative partnerships, holistic and personal care, and community participation, which for students only familiar with clinical recovery from their experience in medical-surgical nursing, or for students whose understanding is that a mental illness is chronic, not easy to treat and likely to require some sort of institutional care eventually, requires some reflection and eventually a shift in outlook.

\section{TEACHING RECOVERY-ORIENTED MENTAL HEALTH NURSING}

Recovery approaches can help students to understand and appreciate "the humanness of patients" (Hunter et al, 2015, p. 32). A priority for developing the future workforce needs to be not just that nurses are skilled but also that they are recovery-focused (Happell et al. 2018).

People with a mental illness have not chosen their illness, they are people like anyone else, with dreams, fears, needs and so on, who we should give opportunities to so they can live a life that is as normal as possible. (Respondent I7 in Rodriguez-Almagro et al., 2019); however in spite of one nursing student in the study showing a good understanding of recovery, the study overall showed a moderate level of stigma towards people with mental health disorders among Spanish nursing students.

An Australian study differentiated between personal recovery and clinical recovery but a small number of nursing students who responded sometimes confused the two both at the start and at the end of a clinical placement in mental health, though final results showed positive attitudes to recovery at the start of a clinical placement and improved attitudes after its completion along with consistent understanding of personal recovery (Foster et al., 2019). Another Australian study (McKenna et al., 2016) identified a tension between psychosocial rehabilitation where clinical staff decided on the skills which their patients or clients required to recover, and a true recovery-focused service, and found that staff struggled with the difference between clinical recovery and personal recovery. When student nurses on a short placement see people in the acute phase of a mental illness they do not factor in recovery as a probability or even as a possibility.

An attempt to show alternatives was provided by one nursing program in the US, which added a community placement to the acute placement, and also included contact with people with lived experience of particular disorders being studied, and reflections by the students on personal experience with mental illness, self-identified personal stigmatising attitudes and those in the wider community (Carroll, 2018).

That there can be a mismatch between the understanding of an experienced mental health nurse working with a recovery focus and that of an undergraduate student is demonstrated by the following:

I have been a MHN for 12 years. During that time I have worked a variety of locations and services, which as you can imagine had their own philosophies and standards of care. I learned very early that my outlook of what a Mental Health Nurse should offer and what was being offered in Mental Health Acute settings didn't align. Someone asked me the other day what they would need to be a MHN and I said, that it's easy really, you just have to be kind. And I believe that wholeheartedly, you have to be kind and particularly in the Recovery sense, you have to believe that people are capable of making decisions for themselves and be able as an MHN to support that. I am kind, and I care a lot for people. I don't believe acute MH settings care for people, and that why I and my recovery orientation don't fit in those settings (experienced mental health nurse working in Rehabilitation).

The understanding of a student is more focused on illness, provision of appropriate referrals and supports, and working towards a clinical recovery. The goal is for "a better mind set" but it is still staff who "get the patient set up".

Recovery in mental health refers to getting the patients back to a stable mental health or to their base line function. It includes providing them with coping mechanisms to help them recognise when symptoms are happening again and how to get back on track to minimise the chances of relapse. 
Recovery also focuses on getting the patient set up for when they leave the ward. This may include getting social workers in to help with accommodation or help get a resume in place for when they leave to get a job.

Recovery in mental health is important and is when the patient has a better mind set and can make informed, sensible and rational decisions for themselves (Heidi Aarons, student nurse).

A very different viewpoint comes from a man with lived experience of schizophrenia:- My experience of knowing many people living with schizophrenia has been that performance levels are often higher than might typically be expected (and health professionals and textbooks imply). For many people recovery is experienced as a struggle to get by; but it is worth the effort! (Simon Swinson in Hazelton \& Swinson (2018) p. 301).

The experience of limited performance expectation is a common theme described by consumers (Hancock et al., 2018). Lietz et al. (2014) similarly report that upper limits and future capacity can be viewed negatively by health professionals; with limiting beliefs, language and expectations particularly damaging for the personal hope of the consumer. With this in mind, it is interesting to see that the student's perspective on recovery includes a relatively passive approach from the consumer and a more active role of the nurse. This could be viewed as a reflection of this expectation limitation as described by the consumer above. Whereas the experienced mental health nurse promotes capability and independent decision making, the student nurse describes disability and an inability to make rational decisions without support. However this philosophical difference in understanding is not surprising, given that in 2015 a study demonstrated that even experienced mental health nurses will sometimes have a clinical view of personal recovery. This belief can be influenced by other nurses, theoretical misunderstanding and organisational priorities which serve the organisation over the individual (Coffey et al., 2019; Le Boutillier et al., 2015). It is understandable, when viewed in this context, that there is a philosophical mismatch seen in universities if it is also present within mental health services and organisations.

\section{STIGMA}

An awareness of the pervasive influence of stigma on personal and community attitudes, and so on an understanding of recovery in mental health nursing, is important for student nurses to develop. Stigma begins as a public view when the population as a whole believes and endorses stereotypes about a particular group with resultant discrimination against them, and then becomes self-stigma where an affected person also believes these prejudiced ideas and internalises them (Corrigan \& Nieweglowski, 2019). From prejudiced and stereotypical negative beliefs comes a negative re- sponse and this is followed by discriminatory behaviour.

"Stigma cuts into the core of recovery because it oppresses the very spirit that is essential to the recovery process" (Delaney, 2012, p. 333). To provide recovery-focused care nurses need to be person-centred and promote the autonomy of the person with the mental health disorder; stigmatising attitudes cut into the very heart of this process as nurses bring negative perceptions into their practice. Where there is no hope and an environment which fosters this lack of hope, recovery cannot flourish.

Clinical placements which are autonomy-supportive (i.e. which support student autonomy) have been found to decrease stigmatising attitudes (Perlman et al., 2020). Authentic role plays where nursing students acted an exaggerated stigmatising response towards people with mental illness, and real-world contact with stable patients, decreased stigmatising attitudes among Chinese nursing students (Gu et al., 2021). A study of Indian nursing students found that while students held positive attitudes towards people with mental illness, they still maintained negative stereotypes about mental illness (Poreddi et al., 2015). Another Indian study found nursing students rated highly on stereotyping of people with mental illness and pessimistic prediction for them (Sreeraj et al., 2017); but in a comparison between medical and nursing students nursing students were more positive about treatment of and reintegration into society of people with mental illness (Poreddi et al., 2017).

A PBL-based mental health nursing education program produced a positive change in student attitudes towards mental illness compared with a traditional learning method (Duman et al., 2017). Problem-Based Learning (PBL) provides practice in realistic clinical scenarios which students are likely to encounter during clinical practice (Happell, 2009). Authentic stories from clinical practice may be used in the same way (Treloar et al., 2018). More personal and professional exposure to people with mental illness produces subjectively more positive attitudes in nursing students, with personal exposure being a stronger influencing factor (Hawthorne et al., 2020). In a study of nursing students in Singapore, based on a negative correlation between close contact with people having mental illness and stigma, it was recommended that nursing students have more contact with these people before clinical placement (Samari et al, 2018).

\section{HOW DO ATTITUDES AND VALUES INFORM UNDERSTANDING OF RECOVERY?}

Attitude involves an evaluation, the objects of that evaluation, and the tendency to respond either positively or negatively based 
on past experience (Happell \& Gaskin, 2012).

Common beliefs about poor prognosis of psychiatric patients are seen as demonstrating both the ineffectiveness of psychiatric treatment and the lack of a scientific foundation for the discipline, but embracing a holistic framework consistent with nursing's person-centred and recovery oriented principles and the integration of mental and physical health services are strategies which could combat these misconceptions (Flaskerud 2018). A focus on what recovery means can also change these negative attitudes; whereas allowing the objectivity of science to carry more weight than lived experience is a barrier to this change of negative attitudes.

If people with lived experience are involved in the development of nursing curricula the course will educate student nurses to be more responsive to the actual needs of consumers and will also give student nurses insights into consumers as people rather than just as service users (Happell et al., 2011). Attitudinal change is an important component of a nursing course though a study in India found that Indian nursing students had a pessimistic attitude towards recovery and rehabilitation of people with a mental health disorder (Poreddi et al., 2014).

\section{IS RECOVERY IN MENTAL HEALTH NURSING A THRESHOLD CONCEPT?}

Students enter a liminal space when they struggle to understand a new concept which is not part of their own personal or clinical experience or their professional knowledge. Such a concept has been described as a threshold concept. Recovery can be a new concept to undergraduate mental health nursing students if their outlook is based on stigmatising attitudes gained in the community and can prove challenging if their idea of recovery is restricted to clinical recovery as seen in medical/surgical wards. They need to expand their view and move from a specific idea of recovery to one which is broader and has a different focus.

The liminal space is described by Reeping (2020) as a place between two existential planes. It is one of the key attributes of threshold concepts which he lists as:

Bounded (may have only a specific purpose in a discipline)

Discursive (can involve an extended or enhanced use of language) Integrative (brings together several disparate concepts, perhaps in an unexpected way)

Irreversible (can be difficult to 'unlearn')

Liminality (there is no straight path in learning the concept; involves a conceptual back-and-forth)

Reconstitutive (may cause a shift in the student's subjectivity)

Troublesome (likely to be an issue for the student to learn; may be counterintuitive).
Transformative (changes the way the student sees/thinks about the discipline).

Hedges (2015) argues that transformation in students may not be emphasised in teaching and is not measured in assessment items; it involves a shift in world view. More recent additions to these descriptors of threshold concepts include integration of new discipline-specific mental or verbal language (Nicola-Richmond et al., 2018). Assessing a shift in world view and in the language used to express this is difficult to assess objectively.

Brown et al., (2021) remind us that threshold concepts are not the same as course learning outcomes and recommend that they be used as less prescriptive reflective prompts to stimulate discussions. They note that floating signifiers can mean different things to different people and that prescriptive application of threshold concepts can create power imbalance between staff and students as faculty determine what body of knowledge is essential to acquire; these authors also call into question the role of threshold concepts in the formation of professional identity. Yet threshold concepts can offer a way to streamline what is taught in a way that is valuable to both teachers and students even though students do not always know what they need to learn (Barradell, 2013).

One study in Turkey noted that nursing students mostly found mental health patients to be "unpredictable, dangerous and incurable" (Inan et al., 2019, p. 201) and that though perceptions of dangerousness changed after the mental health nursing module was run, there was no change in scores for views on incurability and disturbances in interpersonal relationships. Perceptions of dangerousness and incurability changed after clinical placement; and after an anti-stigma program was run, perceptions about all three changed positively.

The move from viewing mental health patients as "unpredictable, dangerous and incurable" to people capable of choosing their supports so that they can live their best possible life even with some continuing symptoms is what is needed if students are to embrace recovery-oriented mental health nursing care to the full.

Stacey and Stickley (2012) argue that recovery in mental health nursing is a threshold concept because it asks students to re-assess their beliefs and prejudices, saying that students may fail to gain more than a superficial medically-determined understanding because of "the ambiguous and subjectively determined meaning of recovery" (p. 536). Nurse educators and tutors may underestimate how difficult it can be for students new to mental health nursing and without their own lived experience of mental illness to shift their view of recovery. What tutors take for granted can be a new area for reflection and learning for students.

A student-centred educational approach recognises challenges to learning experienced by students (Kistler \& Tyndall 2021). Rec- 
ommendations byHunter et al. (2015) are to use existing curricula to provide a more comprehensive view of the role of the mental health nurse, to involve service users in teaching, and to include guided critical reflections and simulated illness experiences.

\section{TEACHING RECOVERY IN MENTAL HEALTH NURSING}

Van Manen (1990) identified the need for anticipatory reflection, i.e. thinking before starting teaching. After this comes contemporaneous reflection based on what happens as we teach, and this allows best use being made of the teachable moment. This is followed by what McLeod and Reynolds (2007) call reflection on action as what has been taught is evaluated; these authors describe anticipatory reflection as reflection for action and contemporaneous reflection as reflection in action, saying that if the right questions are asked throughout the teaching cycle reflection can then become the catalyst for change in teaching and learning. A clarification of values is central to the teaching of recovery as values underpin the importance of actions and beliefs (McLeod \& Reynolds, 2007) and are a composite of concepts, philosophy and aims. Negative or stigmatising attitudes will affect values.

"Effective teachers consider what they are trying to achieve, how they intend to achieve it and why they are doing it" (McLeod \& Reynolds, 2007, p. 69). The. undergraduate mental health nursing course aims to achieve an understanding of recovery-focused mental health nursing care. However this concept is not embedded in all course material; rather it appears to be an addition. Students are introduced to the topics of anxiety, major depressive disorder and schizophrenia through the teaching videos from the Wiimali website. These vignettes, although providing a realistic basic portrayal of people trying to manage these conditions, are not specifically recovery-focused which means that students only see these people in the acute phase of their illness and never see them as they recover. The role of the mental health professional is key and the focus is on risk management, patient safety, and appropriate medication. If students then have a clinical placement in an acute area they are never introduced to rehabilitation and recovery, with the result that their perception and impression of mental health patients may remain stuck on "incurable".

Assessment is divided into diagnostic, formative and summative (McLeod \& Reynolds, 2007). Diagnostic establishes a starting point for new learning, formative focuses on the process of learning and in this feedback to learners is essential. Summative assessment deals with the final product and to be dependable it should show reliability (no errors in formulation or assessment of the task, fair for a diverse range of students, with some certainty that similar results would occur at a different time and place, and manageable); and valid (related to the appropriate outcome, with information to guide future learning, with both teacher and learners aware of what the procedure aims to achieve and with the content appropriate for the outcome). Significantly, authentic assessment requires learners to demonstrate what they have learned in ways similar to how it is demonstrated in the broader community and involves an integrated approach which uses knowledge, skills and values from several outcomes and content areas. Learners need to be both self-directed and able to reflect on their learning, and to produce, rather than reproduce, knowledge (McLeod \& Reynolds, 2007). However if students do not meet consumers who are recovering or access teaching materials which are predominantly recovery-focused, a final assessment requiring demonstration of their understanding of recovery-oriented mental health nursing is likely to be taxing.

\section{MODIFYING TEACHING MATERIALS TO EMBED RECOVERY}

The focus on recovery-oriented mental health nursing care in the course was not embedded in the course from when it was first developed and the teaching videos used do not depict people in recovery. If a student's clinical placement takes place in an acute setting there will be no opportunity to explore the concept there either, even if academic teaching staff demonstrate their own recovery focus during classes.Recovery cannot be an "add-on"; it needs to be a core concept in the whole course and demonstrated in all course material.

\section{RECOMMENDATIONS}

In order to show recovery-focused mental health nursing the course needed to have this concept embedded from the beginning and more emphasis placed on recovery throughout the course. Teaching videos should show people recovering in the community in partnership with mental health professionals. The course should use recovery-oriented language and avoid terms which are negative or which perpetuate stigma. The consumer experience should be part of all course materials rather than a single stand alone lecture as it is currently. Tutors should have current clinical practice roles as well as teaching roles so that they can demonstrate a recovery focus. Assignments should be specific about how the student's understanding of recovery is to be demonstrated and emphasise that this should be a personal understanding based on several weeks of reflection rather than a textbook definition added at the end of the assignment. 


\section{CONCLUSIONS}

To a student beginning mental health nursing, the word recovery suggests clinical recovery, and understanding is based on previous experience in medical/surgical nursing; to a consumer with lived experience it is part of a journey towards a better future even if this involves some struggle; to an experienced mental health nurse it calls for reflection on type of nursing care to be offered, aims and how it should be delivered.

Each of the reflections above (from a student, from a consumer with lived experience, from an experienced mental health nurse) demonstrate aspects of recovery. The student is still formulating her ideas but knows that nurses help people get back on track so that eventually they can make decisions for themselves; the consumer writes of struggle but says that this struggle is worth it; the mental health nurse speaks of needing to believe that people are capable of making decisions for themselves with the support of nurses who are kind;

A course which effectively embeds recovery in teaching materials needs to allow opportunities to reflect on and develop understanding of these ideas so that even if the clinical placement is in an acute mental health setting students can still look for this personal recovery orientation or identify when it is not present.

Recovery camps are one way to achieve this. Going on holiday implies many skills and attributes not always associated with mental health consumers. There is a sense of wellness and hope, independence, the ability to engage, to plan and organise, and possibly to be accompanied by others with whom the person has strong relationships even if they are not intimate relationships. There is the anticipation of enjoyment and the ability to enjoy. Recovery camps have been used to demonstrate in a practical and experiential way to student nurses what recovery means today (Tapsell et al., 2021) and are a way to marry the consumer experience, with both teaching and learning, and clinical placement.

\section{REFERENCES}

Barradell, S. (2013). The identification of threshold concepts: a review of theoretical complexities and methodological challenges. Higher Education, 65, 265-276.

Brown, M., \& Whybrow, P. \& Finn. (2021). Do we need to close the door on threshold concepts? Teaching and Learning in Medicine.

Carroll, S. (2018). Destigmatizing mental illness: an Innovative Evidence-Based Undergraduate Curriculum. Journal of Psychosocial Nursing and Mental Health Services, 56(5), 50-55.

Chiovitti, R. (2011). Theory of protective empowering for balanc- ing patient safety and choices. Nursing Ethics, 18(1), 88-101.

Coffey, M., Hannigan, B., Barlow, S., Cartwright, M., Cohen, R., \& Faulkner, A., et al. (2019). Recovery-focused mental health care planning and co-ordination in acute inpatient mental health settings: a cross national comparative mixed methods study. BMC Psychiatry, 19, 115.

Corrigan, P., \& Nieweglowski, K. (2019). How does familiarity impact the stigma of mental illness? Clinical Psychology Review, $40,70-80$.

Delaney, K. (2012). Psychiatric mental health nurses: stigma Issue we fail to see. Archives of Psychiatric Nursing, 26(4), 333-335.

Duman, Z., Gunusen, N., Inan, F., Ince, S., \& Sari, A. (2017). Effects of two different psychiatric nursing courses on nursing students' attitudes towards mental illness, perceptions of psychiatric nursing, and career choices. Journal of Professional Nursing, 33, $452-459$.

Flaskerud, J. (2018). Stigma and psychiatric/mental health nursing. Issues in Mental Health Nursing, 39(2), 188-191.

Foster, K., Withers, E., Blanco, T., Lupson, C., Steele, M., \& Giandinoto, J., et al. (2019). Undergraduate nursing students' stigma and recovery attitudes during mental health clinical placement: A pre/post-test survey study. International Journal of Mental Health Nursing, 28, 1068-1080.

Gu, L., Jiao, W., \& Xia, H. \& Yu. (2021). Psychiatric-mental health education with integrated role-play and real-world contact can reduce the stigma of nursing students towards people with mental illness. Nurse Education in Practice, 52, 103009.

Hancock, N., Smith-Merry, J., Jessup, G., Wayland, S., \& Kokany, A. (2018). Understanding the ups and downs of living well: the voices of people experiencing early mental health recovery. BMC Psychiatry, 18, 121.

Happell, B. (2009). Influencing Undergraduate Nursing Students' Attitudes Toward Mental Health Nursing: Acknowledging the Role of Theory. Issues in Mental Health Nursing, 30(1), 39-46.

Happell, B., Moxham, L., \& Platania-Phung, C. (2011). The impact of mental health nursing education on undergraduate nursing students' attitudes to consumer participation. Issues in Mental Health Nursing, 32(2), 108-113.

Happell, B., \& Gaskin, C. (2012). The attitudes of undergraduate nursing students towards mental health nursing: a systematic review. Journal of Clinical Nursing, 22, 148-158.

Happell, B., Platania-Phung, C., Bocking, J., Scholz, B., Horgan, A., \& Manning, F., et al. (2018). Nursing students' attitudes towards people diagnosed with mental illness and mental health nursing: an international project from europe and australia. Issues in Mental Health Nursing, 39(10), 829-839.

Hawthorne, A., Fagan, R., Leaver, E., Baxter, J., \& Logan, P. \& 
Snowden. (2020). Undergraduate nursing and midwifery students' attitudes to mental illness. Nursing Open, 7, 118-1128.

Hazelton, M. \& Swinson, S. (2018). Working in collaboration with people living with schizophrenia and other psychotic disorders. In L. Moxham, M. Hazelton, E. Muir-Cochrane, T. Heffernan, C. Kneisl \& E. Trigoboff (Eds.). Contemporary Psychiatric-Mental Health Nursing. Partnerships in Care (pp. 290-318). Melbourne: Pearson.

Hedges, M. (2015). Embedding threshold concepts: The use of a practice - theory - practice cycle. Waikato Journal of Education, 19(2), 83-92.

Hunter, L., Weber, T., \& Shattell, M. \& Harris. (2015). Nursing students' attitudes about psychiatric mental health nursing. Issues in Mental Health Nursing, 36, 29-34.

Inan, F., Gunusen, N., Duman, Z., \& Ertem, M. (2019). The impact of mental health nursing module, clinical practice and an anti-stigma program on nursing students' attitudes toward mental illness: a quasi-experimental study. Journal of Professional Nursing, 35, 201-208.

Kistler, K. \& Tyndall, D. (2021). Application of the threshold concept framework in nursing. Nurse Educator.

Le Boutillier, C., Chevalier, A., Lawrence, V., Leamy, M., Bird, V., \& Macpherson, R., et al. (2015). Staff understanding of recovery-orientated mental health practice: a systematic review and narrative synthesis. Implementation Science, 10, 87.

Levett-Jones, T., \& Bowen, L. \& Morris. (2015). Enhancing nursing students' understanding of threshold concepts through the use of digital stories and a virtual community called 'Wiimali'. Nurse Education in Practice, 15, 91-96.

Lietz, C., Lacasse, J., \& Cheung, J. (2014). A case study approach to mental health recovery: understanding the importance of trauma-informed care. Ethical Human Psychology and Psychiatry, 16(3), 167-182.

McKenna, B., Oakes, J., Fourniotis, N., Toomey, N., \& Furness, T. (2016). Recovery-oriented mental health practice in a community care unit: an exploratory study. Journal of Forensic Nursing, 12(4), 167-175.

McLeod, J. \& Reynolds, R. (2007). Quality teaching for quality learning. Planning through reflection. south melbourne: Cengage Learning Australia.

Nicola-Richmond, K., Pepin, G., \& Larkin, H. \& Taylor. (2018). Threshold concepts in higher education: a synthesis of the literature relating to measurement of threshold crossing. Higher Education Research and Development, 37(1), 101-114.

Perlman, D., Moxham, L., Patterson, C., Cregan, A., Alford, S., \&
Tapsell, A. (2020). Mental health stigma and undergraduate nursing students: A self-determination theory perspective. Collegian, 27, 226-231.

Poreddi, V., Thimmaiah, R., Pashupu, D., Ramachandra, ., \& Badamath, S. (2014). Undergraduate nursing students' attitudes towards mental illness: implications for specific academic education. Indian Journal of Psychological Medicine, 36(4), 368-372.

Poreddi, V., Thimmaiah, A., Chandra, R., \& BadaMath, S. (2015). Bachelor of nursing students' attitude towards people with mental illness and career choices in psychiatric nursing. an Indian perspective. Investigación y Educación en Enfermería, 33(1), 148-154.

Poreddi, V., Thimmaiah, A., \& BadaMath, S. (2017). Medical and nursing students' attitudes toward mental illness: an Indian perspective. Investigación y educación en enfermería, 34(1), 86-94.

Reeping, D. (2020). Threshold concepts as 'jewels of the curriculum': rare as diamonds or plentiful as cubic zirconia? International Journal for Academic Development, 25(1), 58-70.

Rodriguez-Almagro, J., Hernandez-Martinez, A., Rodriguez-Almagro, D., Quiros-Garcia, J., Solano-Ruiz, M., \& Gomez-Salgado, J. (2019). Level of stigma among spanish nursing students toward mental illness and associated factors: a mixed-methods study. International Journal of Environmental Research and Public Health, 16, 4870.

Samari, E., Seow, E., Chua, B., Ong, H., Abdin, E., \& Chong, S., et al. (2018). Stigma towards people with mental disorders: Perspectives of nursing students. Archives of Psychiatric Nursing, 32, 802-808.

Sreeraj, V., Parija, S., Uvais, N., Mohanty, S., \& Kumar, S. (2017). Indian nursing students' attitudes toward mental illness and persons with mental illness. Industrial Psychiatry Journal, 26(2), 223-227.

Stacey, G., \& Stickley, T. (2012). Recovery as a threshold concept in mental health nurse education. Nurse Education Today, 32, 534-539.

Tapsell, A., Patterson, C., Moxham, L. \& Perlman., \& Perlman, D. (2021). Informing work-integrated learning through Recovery Camp. International Journal of Work-Integrated Learning, 22(1), 73-81.

Treloar, A., Stone, T., \& McMillan, M. (2018). Learning about mental health nursing: linking threshold concepts to practice. Journal of Problem-Based Learning, 5(1), 21-28.

Van Manen, M. (1990). Researching Lived Experience: human science for an action sensitive pedagogy. 